\title{
Light Blue Walls and Tan Flooring: A Culture of Belonging in Engineering Making Spaces (or Not?)
}

\author{
Idalis Villanueva Alarcón ${ }^{1} * \mathbb{C}^{\mathbb{C}}$, Robert Jamaal Downey ${ }^{1}$, Louis Nadelson ${ }^{2}{ }^{\circledR}$, Jana Bouwma-Gearhart ${ }^{3}$ \\ and YoonHa Choi ${ }^{4}$ (D) \\ Engineering Education Department, University of Florida, Gainesville, FL 32611, USA; rdowney1@ufl.edu \\ 2 College of Education, University of Central Arkansas, Conway, AR 72035, USA; Inadelson@uca.edu \\ College of Education, Oregon State University, Corvallis, OR 97331, USA; \\ jana.bouwma-gearhart@oregonstate.edu \\ 4 Biological Sciences, STEM Transformation Institute, Florida International University, Miami, FL 33199, USA; \\ yoonha.choi@fiu.edu \\ * Correspondence: i.villanueva@ufl.edu
}

Citation: Villanueva Alarcón, I.;

Downey, R.J.; Nadelson, L.;

Bouwma-Gearhart, J.; Choi, Y. Light

Blue Walls and Tan Flooring: A

Culture of Belonging in Engineering

Making Spaces (or Not?). Educ. Sci.

2021, 11, 559. https://doi.org/

10.3390/educsci11090559

Academic Editor: AMM Sharif Ullah

Received: 12 August 2021

Accepted: 14 September 2021

Published: 18 September 2021

Publisher's Note: MDPI stays neutral with regard to jurisdictional claims in published maps and institutional affiliations.

Copyright: (C) 2021 by the authors Licensee MDPI, Basel, Switzerland. This article is an open access article distributed under the terms and conditions of the Creative Commons Attribution (CC BY) license (https:// creativecommons.org/licenses/by/ $4.0 /)$

\begin{abstract}
The motivation for this exploratory qualitative study is to understand what a culture of belonging may look like across six engineering education making spaces in institutions of higher education in the U.S. The research question for this study was: In what ways are the management, instructors, and staff operating engineering education making spaces influencing a culture of belonging (if any) for engineering students? We examined the transcripts of semi-structured interviews of 49 faculty members and 29 members of management/staff of making spaces, using thematic coding. From the data, we identified four themes that described the culture of belonging being created in these six engineering making spaces: (a) a 'closed loop' culture for inclusion, diversity, equity, and access; (b) a 'transactional, dichotomous' culture; (c) a 'band-aid, masquerading' culture; (d) a potential 'boundary-crossing' culture. Our primary conclusion was that created cultures in engineering making spaces are extensions of normative cultures found in traditional engineering classrooms. Additionally, while making spaces were attempting to change this culture in their physical infrastructures, it was deemed that the space leadership needs to expand hiring strategies, the nature of making activities, the ambient/physical appearance of the space, disciplines, and required expertise, to create a truly inclusive and equitable culture of belonging.
\end{abstract}

Keywords: engineering; culture; belonging; makerspaces; making spaces

\section{Introduction}

So, this year, you know I have 40 employees: half are women and half are men. And in the machine shop it's about the same percentage as far as support goes. So, we try to make it a very inviting and warm feeling. That's why we have the light blue walls and the tan flooring. We asked quite a few females on our staff, you know, what color you like and so it was, alright, we are going with this ... Awesome, so they had some input on that, so that yeah that makes a difference ... then to feel some ownership and to feel like they are a part of this space. Yeah, any barriers we can break down here ... (Director, Lead).

In spaces designed for making within undergraduate engineering education (e.g., makerspaces, prototyping centers, machine shops), individuals that work in these spaces help students learn about design and development [1,2] of products and prototypes. Through sustained interactions with students, leadership, management and staff in these spaces anticipate that space users (students) will apply what they learn in their coursework and develop workplace skills connected to prototyping [3-5].

At universities, spaces for making are designed for learning and instruction and may vary by their home disciplinary department or college. For example, in engineering, 
these types of spaces are used to support classroom instruction and aid students in career preparation via prototyping experiences and activities [1]. It is also anticipated that when students engage with these types of career-forming activities, there is a greater likelihood that students will persist in their degrees $[3,6]$. Building such a space may represent a noble start; however, it may not be sufficient to attract a diverse population of users [7-12]. Literature points to a growing concern by makerspace leaders that despite their efforts to promote diversity, equity, and inclusion, not all intended users participate in these spaces [7-12].

Designing engineering making spaces requires an intentional approach to alleviate potential exclusion of minority groups in these spaces [9-11]. Use of the spaces must also consider both sociocultural needs of students [12] and how belonging is engendered [10,13]. For the latter point, the term 'belonging' in the context of engineering making spaces is not well understood. The few studies that have sought to understand belonging in makerspaces have defined the construct as a connection to others with peers in the space, being accepted and integrated into a group $[10,14]$. Belonging is believed to begin with student access to the spaces $[3,4,10,11]$. Understanding the relationships between access and belonging in the context of engineering making spaces requires that the goals around diversity, equity, and inclusion are met [11]. For example, Villanueva Alarcón and others [11] recently explored and expanded upon current definitions of 'access' in the context of university making spaces using semi-structured interviews with members of engineering making space management and staff $[3,4,8,10,12,13]$. The latter scholars found that for equity of access to occur, making spaces should: (a) be designed and operated for multiple points of student entry (via course offerings in the space); (b) be operated to facilitate effective student making processes and pathways in their engineering education through competency-building activities, certifications, and trainings; (c) include considerations of the unintended burdens and consequences for expanding access such as purchasing of equipment and costs and adding or removing personnel; and (d) leverage a culture of belonging for increased student "membership (sense of community) and equity (freedom from bias, prejudice, injustice)" [11] (p. 10). The 'culture of belonging' was suggested to be a large barrier for equity amongst engineering making spaces as they appeared to "operate within a closed loop that limited different identities beyond the omnipresent white men in engineering" [11] (p. 13).

Our work seeks to expand our understanding of the culture of belonging in engineering making spaces. In line with our prior research [11], we gathered data from the manager or directors, instructors, and staff leading and supporting these spaces. The long-term goal of this study is to provide a classification of engineering making spaces that leaders can use to assess the potential characteristics (or gaps) of cultures of belonging in their spaces. Our results, discussions, and recommendations throughout the paper aim to provide some guidelines that can propel making space leaders for meaningful changes through a culture of belonging, in the future.

\section{Relevant Literature}

\subsection{Culture of Maker/Making Spaces in Education Spheres}

Generally, makerspace cultures involve a hands-on, do-it-yourself philosophy revolving around the creation, modification, or repair of products [15]. In addition to makerspaces providing participants with these creative design opportunities, the culture of traditional makerspaces is based on the concept of collectivism, where participating members of the community benefit by sharing skills and knowledge with each other [16]. Collectivist environments are social spaces where mentorship, cooperation, and transference readily happen.

The design and operation of a makerspace influences the cultural environment of these spaces. For example, for non-technical, artisan-focused makerspaces, participants are encouraged to share knowledge and resources with institutional and regional communities through local gathering and community events [15], thus promoting collectivism. On the 
other hand, for technology-focused makerspaces, scholars have suggested that in these spaces, "there were almost no references to sharing knowledge and resources with the institutional and surrounding communities" [15] (p. 15) and were instead more focused on competition. The competitive environment instead promotes meritocratic and biased cultures that accommodate a specific type of participant, which is evidenced by the lack of diversity in many science, technology, engineering, and math (STEM)-focused makerspaces [17]. Due to the stark differences between non-technical and technically focused makerspaces, many scholars, and leaders in institutions of higher education are deviating from using the term 'makerspace' in recognition of its different cultural influences compared to traditional community makerspaces [1]. For such reason, from this point forward, most of this work will refer to these spaces as 'making spaces'.

Although university making spaces are believed to have the potential to tighten the relationships between informal and formal learning environments [18], scholars are finding racialized differences amongst these making spaces. For example, in engineering, Greene and colleagues [9] found that while making spaces overall promote agency and engineering identity for Black male undergraduate students, if the making spaces were housed in a Historically White Institution, the heteronormative culture of engineering supersedes what the space leaders intended to promote (e.g., equity). Vossoughi et al. [19] warned against uncritically creating and conceiving educational making spaces as it serves to continue the heteronormative cultures present in engineering classrooms. Furthermore, Vossoughi et al. [19] argued that the ways that making and equity are implemented by educational making space leaders can serve to either restrict or expand the liberatory educational experiences of working-class students and students of color. Barton, Tan, and Greenberg [20] noted that those educational making spaces that have reached beyond the dominant populations "are the exception and not the norm" (p. 30).

The planning and designs of educational making spaces, which typically focuses on new equipment, training, and tools [3], if not considered critically, risk creating unintentional cultures that negatively affect equitable student participation and distribution of benefits [15]. How leaders in these spaces and programs design and view 'access' and 'inclusion,', how they equate inclusion to 'fairness' or 'sameness' [21], or how they consider cultural factors such as membership [10], influences the ways that the learning goals of the making activities in these spaces are or are not "implicitly rooted in the experiences of dominant populations" [19] (p. 214). What counts as 'making' by the spaces' leadership, management and staff, must include a lens that considers the historical and cultural backgrounds of its users. Otherwise, the design and building of 'neutral' making activities (e.g., 3-D printed objects) [19] will result in the same normative cultures found in engineering.

There is a growing call by scholars and educators to intentionally create cultures in making spaces that explicitly cue to students a heightened sense of belonging via membership [10]. For example, Kellam and colleagues [22] suggested that creating equitable engineering making spaces that center around culturally relevant activities result in failforward cultures. Fail-forward cultures are at the heart of equity in that they foster a culture of trust. In fail-forward cultures, students are not penalized for using equipment or materials; instead, these are free and available to support student learning, whether the project is personal or part of their coursework [22]. Fail-forward cultures do not reward 'intellectual and cultural gatekeepers' of the space [19]. Rather, in fail-forward cultures, all students can safely share their perspectives and participate as themselves without being afraid of being excluded [23]. So, equity in this sense, involves a recognition of all students as contributors to the space and not just a receiver of the space.

\subsection{Individual Belonging versus a Culture of Belonging of Maker/Making Spaces}

An individual's sense of belonging can be defined as

"[T]he experience of personal involvement in a system or environment so that persons feel themselves to be an integral part of that system or environment 
... A system can be a relationship or organization, and an environment can be natural or cultural." [24] (pp. 172, 173)

As stated in Self-Determination Theory [25,26], individuals must first experience support in ways that lead to a sense of belonging with other individuals and with one's community. Belonging may range from being "connected to others, to caring for and being cared by those others" [27] (p. 1196). When belonging is cued by the dominant community, non-dominant groups may compensate by actively seeking a belonging that may not necessarily be aligned with their historical and cultural backgrounds [19] or identities.

Amongst educational making spaces, an individual's sense of belonging is linked to one's feelings of having common characteristics within the space [19], which may be determined by what projects, activities, and type of expertise are present in the space [10] and being able to build positive relations with others in the space [14]. Thus, external cues (either in the ambient environment or in the physical infrastructure of the space), making activities (e.g., artifacts and projects), and social interactions (or lack of) influence individuals' sense of belonging in these spaces [8]. As stated by Alexander [28],

"Passing ... as both a means of maintaining cultural membership, by assuming the necessary and performative strategies that signal membership, as well as the conscious and unconscious choice to engage other performances that situate... identity ... is a reflection of one's positionality-knowing that the existential accomplishments of passing always reside in liminality." (p. 72)

Yet, this liminality, at the intersection of culture and belonging is seldom explored nationally, and it is largely viewed as being absent in making research reports [15].

The lack of scholarly work on the cultures of educational making spaces and the connection to belonging may significantly narrow our view of the utility and benefit of these spaces for different populations of users. Kim et al. [15] maintain that the benefits of making spaces for users "lies not in the equipment or procedures of making, but rather in the culture they enable, nurturing and promoting learning through creation, collaboration, and individual agency (control, autonomy, and choice)" (p. 1). For making spaces, the distinction between an individual's sense of belonging and a culture of belonging is essential. Through a culture of belonging, people are encouraged to be authentic and share their diverse perspectives [29]; as a result, cultures shift from "awareness to empathy" to actively demonstrate "the behaviors of inclusive leadership that cultivates a greater sense of trust" (p. 11). A lack of intentionality for creating a culture of belonging restricts some of its users to connect observationally, motivationally, or cognitively with the space. The lack of connections only serves to further strengthen the cultural forces that communicate exclusion for minoritized groups in these making spaces.

To our knowledge, the culture of belonging in making spaces and the consideration of different domains of diversity (e.g., gender, race, ethnicity) has not been empirically documented. There is evidence supporting the need to consider culture [15] and to consider individual belonging [3], yet there is a gap in the literature exploring the intersection of culture and belonging. We argue that this intersection, a culture of belonging, in educational making spaces needs to be explored due to its association with decision-making, designs, and operations of the spaces [29], which is essential for attending to issues of exclusivity and inequity. For this work, we will build on prior studies $[3,4,11]$ and seek to add to the literature regarding what a culture of belonging may look like for engineering making spaces.

\section{Materials and Methods}

\subsection{Research Question}

Our overarching research question was: In what ways are the management, instructors, and staff operating engineering education making spaces influencing a culture of belonging (if any) for engineering students? We speculate that if an engineering education making space was 
intentionally designed for a culture of belonging, then design of its space and connected activities would increase opportunities for access, equity, and inclusion.

To answer our research question, we visited multiple university engineering making spaces across the U.S. and gathered data through interviews and observations of the space leaders, directors, managers, staff, student-staff, faculty instructors, and students. The elements used for this study are explained in more detail below.

\subsection{Study Sites}

Our research is part of a larger-scale study documenting the experiences of engineering education making spaces' leaders, directors, managers, staff, faculty members, and students and staff who integrate teaching and mentoring opportunities in these spaces $[1,3,4,6,11,30]$. The overall purpose of our project was to explore how engineering education making spaces, located in Colleges of Engineering in the U.S.A., are integrated into the curriculum and how the design of the making spaces influences student access, belonging, motivation, and professional identity development. All the making spaces were housed in doctoral degree-granting universities with high research activities (Indiana University Center for Postsecondary Education, 2021). Two of the sites were in the Southwest region of the U.S.A., one was in the Midwest part of the U.S.A., and the remaining sites were in the Western part of the U.S.A. We gathered data using surveys, semi-structured interviews, observational data, and our field notes. We analyzed the semi-structured interview data and memos/field notes from our interactions with the faculty members, management, and staff as the primary source of data for our examination of issues of belonging and culture within the making spaces. For all site visits, Institutional Review Board of human subjects was attained from the home institutions of the principal investigators for the duration of this funded project.

\subsection{Data Sources}

From 2017 to 2019, members of the research team conducted an average of two visits at different time points (approximately 6 or more months apart) to six different engineering education making spaces. A total of 45 (faculty members), 29 (staff), and 148 (undergraduate engineering students) semi-structured interviews were collected across the six sites. Our prior research has explored the experiences and perceptions of space leaders, directors, and managers (e.g., administrators with and without instructional roles), staff (e.g., industrial specialists with and without instructional roles), student-staff, and faculty members integrating the engineering making spaces into their instruction, and students using the spaces $[3,4,11,13,14,30]$. We also explored these interviews from the lens of equity of access [11] and found that access was connected to a culture of belonging in these spaces. The connection motivated us to document the culture of belonging in the engineering education making spaces with a specific focus on the leadership, manager, faculty, and staff interviews.

While we used the student interviews solely to confirm our findings, these data sources were not included in our main data analysis since it was outside of the scope of this work. The semi-structured interview questions have been published elsewhere $[4,13,30,31]$ but we are including a summary of the belonging questions in Table 1. It is important to note that we did not directly seek perspectives of the culture of belonging in the spaces, yet multiple participants spoke about the culture of their making space. 
Table 1. Belonging-Related Semi-Structured Interview Questions During Site Visits.

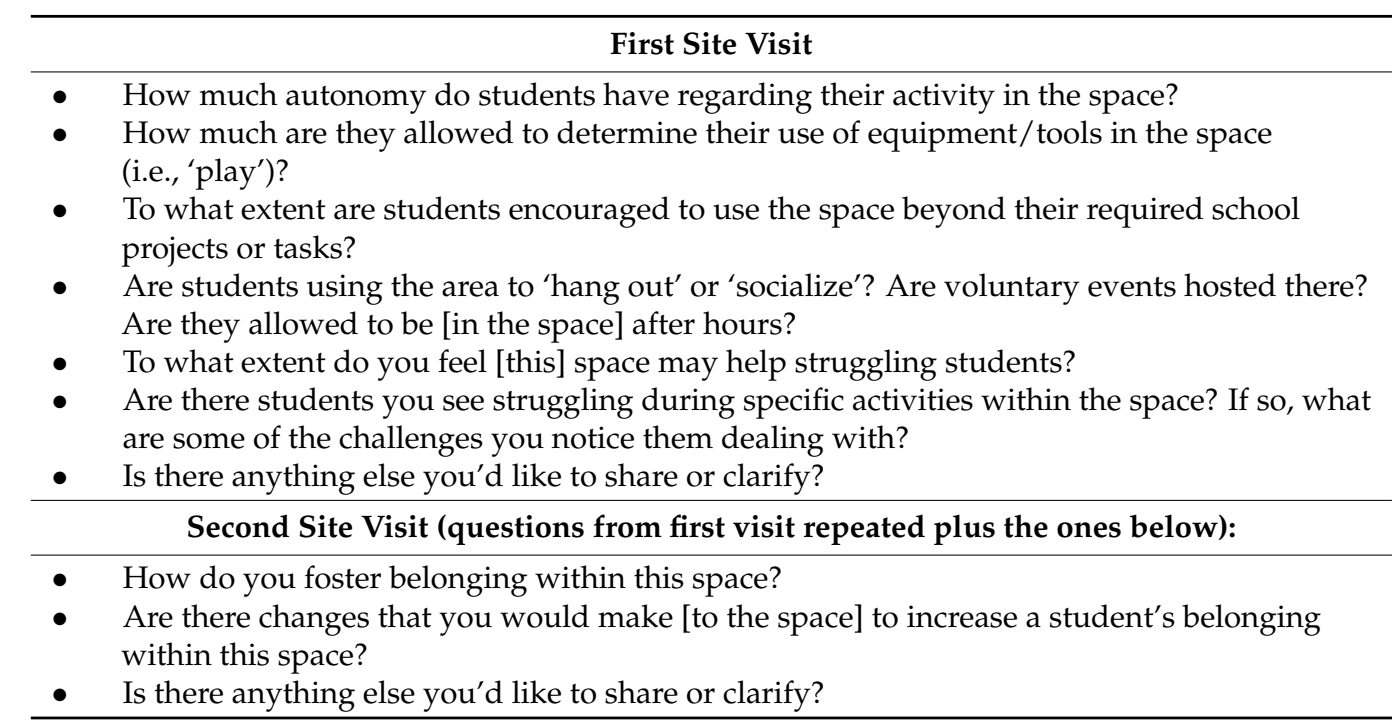

\subsection{Data Analysis}

We used a phenomenological approach [32] to analyze our data to expose the common themes of cultures, which involves identifying the most common and salient descriptors of the experiences of the participants. The interview transcripts were first uploaded into the coding program, NVivo, for several rounds of thematic coding. The first round of coding allowed the researchers to gain a general understanding of the data; this process yielded 32 categories. The second round of coding was directed towards the phenomenon under study to decipher any nuances embedded within these categories and was subsequently collapsed into four themes. These themes were discussed at length between the first and second author and corroborated with the remaining authors until consensus was achieved. Once the sub-categories were identified, representative quotes from these themes were collected onto one main document for further analysis and verification. As a final round of analysis, we conducted member-checking [32] of our findings by comparing our analysis with student interviews; this allowed for confirmation of our analysis results and trustworthiness of our data. As stated previously, student interviews have been already analyzed in previous publications $[3,4,11,13,14,30]$ and was only used for verification of our findings in this work.

\section{Results and Discussion}

We identified four themes aligned with a culture of belonging being created in these six engineering making spaces: (A) a 'closed loop' culture for inclusion, diversity, equity, and access; (B) a 'transactional, dichotomous' culture; (C) a 'band-aid, masquerading' culture; (D) a potential 'boundary-crossing' culture. Themes A and B describe the existing culture of making spaces as perceived by the interviewees, while theme $C$ describes the approach that making space leaders were taking to address issues of inclusion, diversity, equity, and access. Finally, theme D points to the possibility of creating a making space culture that promotes belonging, going beyond the heteronormative culture of engineering.

\section{Theme A: A 'closed loop' culture for inclusion, diversity, equity, and access.}

We considered a 'closed loop' culture occurring whenever an engineering making space did not acknowledge the diverse identities of students who are likely entering the space and rather, focused on the students who were actively using the space. In other words, the conversations among faculty, staff, and administrators in these engineering making spaces centered around the students who are in front of them but did not question who is in the room and why other students from minoritized groups are not there. Additionally, these space leaders tended to hire personnel, particularly student-staff, from within. While 
it makes pragmatic sense to hire those who already utilize (or master) the equipment in the space, this perpetuates what already exists-a hegemonic, majority population and culture in engineering:

And I think part of that is because student-staff are involved in hiring, even undergraduate student staff are. So, they're pretty conscientious of like not just what are your skills, you know, not just your technical skills, but what's your potential for gaining those skills, and how can you gel as an employee and be, you know, [name omitted] is I think very conscientious of not wanting it to be that like hacker labby [sic] dark den feels in here. And so, a lot of everything that we do is based on like how do you cultivate in the workers, in the people you choose to work here, that sense of like community, while also not making it this like insular, cliquey, masculine thing. (Assistant manager, student-staff)

While they also post it, they tend to look over the names of the workshops and machine logs to see what names regularly pop up. And while this may seem good so that you have people that know the equipment, what it does is not open access much to those not there. It might breed a culture that circles itself without many access doors for outsiders ... . . If they're already pulling from the preexisting pool, how does that do for access and belonging? ... Graduates included ... They tend (or have been lucky) to keep the same graduate students for stretches of time. (Employee, student-staff)

We also found that a 'closed loop' culture resulted from an intentional omission of different users of the space based upon their acquired technical skills and/or disciplinary differences compared to engineering:

But just my personal opinion, I don't think they're very nice to people who are outside of the school. Outside of the engineering school. It's like, they don't think the same. Because you have to have drawings, CAD drawings before you use these services. If you're in the art school, you're not gonna know how to do that, or probably be familiar with what CAD is. And so just denying them at the door because they don't have a drawing, I don't know. That's not very encouraging. (Employee, Student-Staff)

They're like, "So you're in freshman projects." We were like, "Yep." But they're expecting you to be like, "Oh yes. Senior design." So, they have to treat you differently. And I just feel like they don't want to do that. Just because it's like they have to dumb everything down, and they're just like, "That shouldn't be my job." They're like, "You should have learned this in class. (Employee, Student-Staff)

Finally, we found a 'closed loop' culture involved having a 'colorblind' / genderblind' approach in their space. In not acknowledging multiple race and/or gender identities from users in the space, the approaches used by management, staff, or faculty to narrow the diversity gap was superficial at most:

... we are really the technicians the staff most of the faculty members we really do not see gender in here at all. I mean I joke that there are all the same annoying students in here to me. (Director/Lead)

So, this year, you know I have 40 employees: half are women and half are men. And in the machine shop it's about the same percentage as far as support goes. So, we try to make it very inviting and warm feeling. That's why we have the light blue walls and the tan flooring .... Yeah, any barriers we can break down here ... (Director, Lead)

People in search of belonging are looking for a place that accepts them, a place where they can feel wanted and welcomed. "Just as people need to eat and drink, to have security and freedom of movement, so too they need to belong to a group. Deprived of this 
dimension in life, they feel cut-off, lonely, diminished, and unhappy. To be human means to be able to feel at home somewhere ..." " [33] (p.10). As humans, we need to feel that we are an integral role of something bigger than the self; belonging and being accepted into a group provides such structure. Related to making spaces, belonging is vital to creating a space that supports different identities; in the process of recognizing and valuing these differences, more divergent solutions to narrow the diversity gap can be developed.

\section{Theme B: A 'transactional, dichotomous' culture.}

In our view, a 'transactional, dichotomous' culture highlights the discourses that occur when making space managers, directors, faculty members, or staff unintentionally create a dichotomy between their approaches to increase representation in the space and what is being interpreted as needing to 'fit in'. In trying to navigate the making space and meet the requirements of engineering, leaders inadvertently transact (exchange) normative beliefs of the discipline by increasing representation without realizing the dichotomies created through a superficial view of equity in these spaces. For example, in the first quote below, one of the making space leaders/directors stated that the making space culture does not support 'hand-holding' of students; at the same time, this director supports the choice to have more women in the daily operations of the space. While it may not be direct, the statement alludes to a potential leadership decision premised on the expected nurturing role that women are to have with student users in the space. Thus, a dichotomy is created (not handholding versus views on who should 'hand-hold'). The transaction in this case was the number of women hired in the space to guarantee inclusion. In the second example quote, we find a student-staff who admits to the exclusive environment of the making space but who then opted to work in the same space because it looks good on their resume. In this case, while the presence of this student-staff may ignite a culture for meaningful change, the intention behind the individual is self-serving. Thus, a dichotomy is created: seeking a collaborative, supportive culture of the space versus personal gain. In this case, the transactional piece was evidenced in the notion that the student-staff was willing to give up a piece of themselves to 'fit in' the making space.

No one is going to walk over or is going to hold your hand. So that is basically important to us, but I hear of other schools that struggle to get the females to use the shop, so they hold like ladies' nights and stuff like that; we just never needed to and I'm really happy about that. It is also run by women ... (Director/Lead)

I mean, we didn't want to come here. None of my group particularly had a good taste in their mouth afterwards. So, by me deciding to work here, I was like, "First of all, I do need a job" ... this is gonna look great on my resume. (Student-staff)

Furthermore, dichotomies were found on topics related to gender at the expense of the transaction of identity. In the example quote below, we find that while the making space leadership tries to consider students' gender identity, their views are limited solely to a binarized view of gender, forgoing all the other intersectional identities in users. If belonging is something that an individual searches for-yet when the individual is culturally denied belonging due to systematic renunciation and lack of acceptance of varying racial, cultural, and/or gender identities - their belonging becomes unattainable. Consequently, a user may feel obliged to relinquish their identity (a transaction) to assimilate to the cultural norms of a making space to gain belonging (dichotomy).

Before I came here there was another female that I had my position. And um we make sure, also like, because of the teaming, when we assign teams, at times there is an isolated female. We try to make sure the design mentor is female. We are intentionally thinking about this representation. But what makes them rise up, I don't know. Have you met with a design mentor yet? (Staff/ Faculty member) 
We also identified dichotomies at the intersection of race and gender. The following member of student-staff describes her overall experiences in an engineering making space as a woman of color and ethnic minority student and her process in becoming a student worker in the space.

... [I] don't think the maker space didn't do anything to make me feel welcomed or the makers ... So now I'm not talking this is really about the maker space, I'm talking about the people in the maker space, which is part of what makes the whole construct, if you will. So, it's human interactions, at the beginning I was not part of the group and then I was ... It's this kind of passive thing this community and maybe you feel that you don't fit there. So, you can come here. It's bigger like the other space ... this is bigger. If you need help you can ask for help, but I don't know how the community feels here because I haven't spent much time here. (Student-staff)

The need to engage in a transaction of exchanging their identities to acquire a sense belonging in a making space is like issues of the hidden curriculum in engineering. The hidden curriculum includes systemic and structural covert messages conveyed to individuals from their surrounding environments; the message, in this case, may have resulted in an individual decision to negotiate their 'self' to fit in to a culture that is not open to who they truly are [34].

Theme C: A 'band-aid, masquerading' culture.

A 'band-aid, masquerading' culture involves hiring approaches, advertisement, layout and design of the space, or their outreach strategies to promote the space (and the field of engineering) to prospective users (e.g., students). We selected the term 'band-aid' to reflect the superficial approach to remedy issues of inclusion, diversity, equity, access, and belonging rather than taking a deeper, introspective, and reflexive approach $[35,36]$. We use the term 'masquerading' to denote the intentional or unintentional approaches that individuals take to make the space appear welcoming and inclusive when viewed by those not familiar with the space. Masquerading creates a 'smoke and mirrors' phenomenon where the reality of the engineering education culture (e.g., hegemonic, meritocratic, majority-dominated, exclusive to minoritized groups), as published and reported by many authors [37-42], is hidden from prospective users.

Actions like changing the ambient environment or advertising around minority users likely portrays a false perception of the reality of a space or culture. The masquerading phenomenon may be referred to as 'masculine defaults', which is a form of bias whereby the "characteristics and behaviors associated with the male gender role are valued, rewarded, or regarded as standard, normal, neutral, or necessary aspects of a given cultural context" [43] (p. 1024) and any effort to masquerade this culture simply serves to signal the prevalence of that majority culture [44]. The latter phenomenon is evidenced by efforts from leaders in changing the color scheme of an engineering education making space to convey a message of inclusion:

We asked quite a few females on our staff you know what color you like and so it was, alright, we are going with this ... Awesome, so they had some input on that, so that yeah that makes a difference ... then to feel some ownership and to feel like they are a part of this space. Yeah, any barriers we can break down here... (Director/Lead)

We argue that 'band-aid, masquerading' approaches are superficial attempts to enact a culture of belonging that give the appearance of a more inclusive making space environment but whose efforts may fall short in the long run. Band-aid, masquerading approaches are not disruptive enough to change the social system in the spaces, leaving intact the hyper-white-masculine environments that are normally present in engineering. Thus, making space leaders, directors, managers, faculty members, and staff in these spaces are encouraged to not support the "idea that female students may prefer a tidier, less complex looking space as they initiate participation" in these spaces [8] (p. 880), but rather 
to think beyond the physical environment and consider what elements would result in making spaces being truly and sustainably inclusive and in where belonging is valued and enacted. For meaningful change to take place, making space leaders must concentrate on addressing the following questions: 'why are these spaces so white and heteronormative?', while also asking 'how can we create a cultural shift that sees the benefits to a space that fosters different identities?'. Exploring the answers to these questions is outside the scope of our report; yet the questions have high potential for future investigation.

Theme D: A potential 'boundary-crossing' culture.

Many of our findings suggest a need to more critically explore and design making spaces that truly reflects a culture of belonging. To provide an example of what this may entail, we opted to highlight one of the sites where important steps around a culture of belonging are being taken. The making space we highlight below operates as a hybrid between a traditional and an engineering education making space. The site is open for use by both engineering and non-engineering students who participate collaboratively in projects to achieve personal and educational goals. The space is supported by students and staff who are not necessarily part of an engineering school.

We posit that crossing disciplinary boundaries may be an initial step to cue a culture of belonging as diverse perspectives, identities, and experiences are embraced in the making space. As one of the making space faculty members for this site shared:

But we had an intern from the architecture department who was a student who had taken my classes previously and she works a lot with as an architect, large scale things. So, there was a lot of support of people helping the student to build that. So, it did create a sense of community and everybody wanted to make the students succeed with that build contributed to the build. (Faculty member)

Similarly, reflecting upon the boundary-crossing culture of collaboration and inclusion, this student-staff had the following ideas and experiences to share:

There's a lot of art, I think, in engineering [inaudible 00:28:41] . . Because they encourage the cross-disciplines ... all those courses are not in the engineering center, they have their own building. They really want all students to be there. They have their little mini ... I'm gonna say a tiny, mini maker space as well. But they want people from all majors to come there. And they have lots of people who are members there who are not in the engineering school. They've got lots of ..., psychology, just general majors like that coming and using it. Because they're not like, "Where's your CAD drawing?" Like, "Where's this?" They're like, "Come ..." " and it's super informal here. I kind of find this place more professional. Like you can't just waltz in and be like, "So I wanted to build this chair." They're gonna be like, "I can't help you. You don't have a drawing of your chair, what am I supposed to do?" But if you go to the [name omitted] lab, which is the place in the [name omitted] building, they're like, "Yeah, let's all work on it together." Everyone's just ... I was gonna say more friendly. (student-staff)

Our findings regarding a culture of inclusion and collaboration for this theme aligns with the original philosophy and goals for the creation of a community makerspace, which was for people in the community to be "engaged in the creative production of artifacts in their daily lives and who find physical and digital forums to share their processes and products with others" [45] (p. 496). Thus, by aligning engineering education making spaces more closely with the original intent of a makerspace, cultural barriers may begin to dissolve to create meaningful changes that enhance students' belonging in the spaces.

The notion that making spaces serve as places that enable 'boundary-crossings' across multiple communities (e.g., disciplines, expertise level) was discussed in a prior study of engineering making spaces from our group [6]. We recognize the potential for expansion of boundary-crossing cultures in making spaces, particularly with regards to creating cultures of belonging that explicitly addresses and embraces the differences along the lines of race, ethnicity, gender, and discipline of study. 


\section{Recommendations for Engineering Education Making Space Leaders}

The data we shared demonstrate that there are areas of improvement that are needed to enhance the culture of belonging in engineering education making spaces. Thus, as more making spaces are created and integrated into the institution and faculty members and students get more involved in these spaces, it will be important to anticipate who may be in the room, and not just who is currently present in the room.

We also wondered throughout this work if what is being done in engineering making spaces is enough. There is a need for engineering education making space leaders and the individuals involved with the space (e.g., leaders, managers, staff, faculty members, students, etc.), to consider what alternative ways can promote a culture of belonging in the space. Our group compiled some tangible recommendations to guide readers into actions and potential implications of their actions in such making spaces:

Ambient belonging. While the physical environment of the space, as found in theme $\mathrm{C}$ (a 'band-aid, masquerading' culture) could cue belonging, there must be more intentionality in how physical, structural, and cultural components of the space coalesce. For example, physical objects (e.g., color of walls, floor layout, posters, etc.) must align with the structural layout of the space (e.g., Is it open? Is it accessible? Is it inviting?) At the same time, the culture you want to engender in the space must be valued and reflected in this ambient belonging. For example, if you want to be inviting towards people of different gender and racial identities, consider promotional materials to be included in the space at key events during the school year (e.g., Pride History Month, Black History Month, etc.). Consider highlighting student work, both personal and educational, that reflects the diversity of your student users both in the space and in the spaces' websites or social media posts. Share student examples and stories or document approaches that include a component of their culture, community, or family life in the projects they have created; this will be especially important for personal projects created in the space. Ensuring that making activities promote a sociocultural approach can ensure that individuals' funds of knowledge are elevated [46] and that their sense of belonging is improved [10,12,13].

Critical hires. Consider more intentional and critical approaches to hire in the spaces (per our findings on Theme A, B, and D). As you consider this point, consider who may not be in the spaces, and avoid binarizing your population (e.g., female/male; black/white, etc.). All individuals carry rich and complex identities and experiences that should be considered in the hiring process; their presence can help ignite the culture of belonging desired for the space. While expertise is certainly important for the spaces, consider hiring experts outside of engineering (e.g., art, architecture, etc.) to allow a more diverse skillset to be visible and shared amongst the users. If needed, create tutorials or trainings that can be easily disseminated and used over time (e.g., online videos) for the new hires that don't have the expertise needed for an equipment or tool in the making space.

If your making space is not at the point of identifying who could be hired into the space, consider taking a step back and creating an entry/exit interview protocol (with a diversity, equity, inclusion rubric) that includes questions around recommendations to create a more equitable culture in terms of race, gender, and other domains of diversity. Offices related to diversity or hiring at your campus may have similar protocols in place and could potentially make these strategies and tools available for your making space. During the interview process, consider hiring a third-party interviewer or witness to the interview. This may help avoid any potential interviewer bias or coercion when considering who to hire in the space. If hiring is not an area that your making space has control over, due to institutional policies, consider at a minimum to include a climate survey or questionnaire for your making spaces. Sporadically, ask student users and staff to complete this assessment to help gather a sense of what culture is being enacted in the space and/or if the space is encouraging a culture of belonging. This assessment may alternatively be disseminated with the support of instructional faculty who use the space or incorporate classroom activities in the space. 
Community engagement. Collaborate with engineering design groups, local companies, or community partners to create mechanisms by which students can contribute to their discipline or areas of interest. Helping students connect with both personal and professional projects can ensure students are continually motivated and exposed to how the making spaces (and their activities, tools, equipment, etc.) assist their professional formation and role in the community. For example, instead of simply engaging in outreach at a K-12 school to promote the space and the discipline, consider partnering K-12 students with university students. Alternatively, consider bringing K-12 teachers (paid over the summers) to help create projects that connect the community or families to the students. In other words, consider who in the community could be engaged with your space to help promote the culture of belonging desired and consider how the space can contribute to the community.

Equity. Rather than equality, consider equity. Equity considers the systemic tools and barriers that prevent students from fully participating in an activity or space. Equality, on the other hand, creates an invisible margin or goal by which it is expected that everyone will be able to achieve. The main difference between equity and equality is the critical consideration of who is using the space and who is not, while accounting for who may be using the space in the future. We recommend that as you consider potential users, to think about incorporating principles of universal design for learning [47]. While the goal is certainly not to universalize or normalize students' experiences, designing making spaces for a culture of belonging requires a consideration of all potential users. For example, re-look at your space and discuss with your making space staff and affiliated personnel; ask yourselves, 'Is the space accessible to a user with an apparent disability?', 'How about a person with a non-apparent disability?', 'Is the space approachable to non-native speakers?' 'How about international students?', 'How are racial and gender diverse identities being considered or not considered?'. Think critically about who your intended student users are and design around these considerations.

Sponsorship. Garnering donations for materials to reduce student fees associated with the space, engenders motivation and students' desire to be part of the space. Spaces created for cultures of belonging should consider the multiple realities and barriers of students (e.g., financial) that may significantly impact their participation in such as a space. Consider partnering with community or centralized spaces in the university (e.g., library) to identify ways to have a steady stream of materials for students to use. While it may not be a long-term solution, if students are aware of the actions of leaders to consider students' realities, a sense of trust can be formed.

Student-centered. Students need to feel that they are welcome in the space, not just in their participation in the space but also in the design and evolution of the space. To accomplish this, it will be important to gather and consider students' experiences throughout each pivotal point of a making spaces' history. Occasionally ask students what they would change about the space to make it more welcoming and consider including some of their recommendations. As suggested by Masters and colleagues [48], collecting and assessing the data may involve participatory and liberatory methodological approaches for discovering inclusive making spaces. Collecting students' voices and centering the making space around their input and experiences may cue a culture of belonging where students know they are valued and heard. If you situate a making space around the user (student), a culture of belonging will soon follow.

\section{Conclusions}

In our work, we explored the efforts to create a culture of belonging in engineering education spaces for making at six different sites. We found that cultures tend to be extensions of traditional engineering classrooms. Additionally, while the leaders of the making spaces were actively attempting to change the culture in their spaces, we determined that the space leaders needed to seek ways to cross the boundaries of hiring, the nature of making activities, the ambient and physical appearance of the space, involve other non-engineering 
disciplines, and expanding the required expertise and input of users. Engineering education making space leadership, management, staff, and faculty members are encouraged to deeply reflect upon what would remedy the restricted cultures of belonging and think about the future and possibilities of who would feel like they belong in the culture of the space.

Author Contributions: Conceptualization, I.V.A., R.J.D., L.N., Y.C. and J.B.-G.; Data curation, L.N., Y.C., J.B.-G., I.V.A.; Formal analysis, I.V.A. and R.J.D.; Funding acquisition, I.V.A., J.B.-G. and L.N.; Investigation, I.V.A., J.B.-G., Y.C. and L.N.; Methodology, I.V.A., L.N., J.B.-G.; Project administration, I.V.A., J.B.-G. and L.N.; Validation, I.V.A. and R.J.D.; Visualization, R.J.D. and I.V.A.; Writing—original draft, I.V.A., R.J.D.; Writing—review \& editing, I.V.A., R.J.D., Y.C., L.N. and J.B.-G. All authors have read and agreed to the published version of the manuscript.

Funding: This material is based upon work supported in part by the National Science Foundation (NSF) EEC-1664271, 1664272, 1664274, and 2113755. Any opinions, findings, and conclusions or recommendations expressed in this material do not necessarily reflect those of NSF.

Institutional Review Board Statement: Ethical review and approval for this study was provided by the Institutional Review Board of University of Florida (IRB202003240) approved 06 January 2021 upon I.V.A. institutional move from Utah State University. It is important to mention that the Institutional Boards of Oregon State University (protocol code 2019-0052 approved on 16 April 2019), University of Central Arkansas (IRB \#18-138 approved 22 August 2018 with an institutional agreement with Utah State University), were also approved and active during the entire study and grant period.

Informed Consent Statement: Per Institutional Review Board guidelines, all participants provided consent to be in the study.

Data Availability Statement: The data presented in this study are available upon written request with the corresponding author. The data are not publicly available due to confidentiality concerns for participants.

Acknowledgments: We would like to deeply thank the six sites that participated in this study and its participants for allowing us to visit and interact with the people in the spaces. A special thanks for Sarah Lanci, Adam Lenz, Kate Youmans, Cindy Lenhart, Taya Carothers, Darcie Christensen, and all the undergraduate research assistants who have provided their time to the execution of this project throughout the years.

Conflicts of Interest: The authors declare no conflict of interest. The funders had no role in the design of the study; in the collection, analyses, or interpretation of data; in the writing of the manuscript, or in the decision to publish the results.

\section{References}

1. Youmans, K.; Villanueva, I.; Nadelson, L.; Lenz, A. Makerspaces vs. engineering shops: Initial undergraduate student perspectives. In Proceedings of the Institute of Electrical and Electronics Engineers, Frontiers in Education Conference, San Jose, CA, USA, 2-6 October 2018.

2. Youmans, K.; Villanueva, I.; Nadelson, L.; Bouwma-Gearhart, J.; Choi, Y.; Lenhart, C. Beyond making: Application of Constructionist Learning Principles in Engineering Prototyping Centers. In Proceedings of the American Society of Engineering Education Annual Conference and Exposition (virtual), Long Beach, CA, USA, 27-30 June 2021; pp. 1-9.

3. Bouwma-Gearhart, J.; Choi, Y.H.; Lenhart, C.A.; Villanueva, I.; Nadelson, L.S.; Soto, E. Undergraduate students become engineers: The affordances of university-based makerspaces. Sustainability 2021, 13, 1670. [CrossRef]

4. Nadelson, L.; Villanueva, I.; Bouwma-Gearhart, J.; Youmans, K.; Lanci, S.; Lenhart, C.A. Knowledge in the making: What engineering students are learning in makerspaces. In Proceedings of the American Society of Engineering Education Annual Conference \& Exposition, Tampa, FL, USA, 15-19 June 2019.

5. Youmans, K.; Campos, L.; Villanueva, I.; Bouwma-Gearhart, J.; Lenhart, C.; Nadelson, L. Professionalism in engineering prototyping centers: An exploratory study. In Proceedings of the Northern Rocky Mountain Educaitonal Research Association Conference, Denver, CO, USA, 10-11 October 2019.

6. Choi, Y.H.; Bouwma-Gearhart, J.; Lenhart, C.A.; Villanueva, I.; Nadelson, L.S. Student development at the boundaries: Makerspaces as affordances for engineering students' development. Sustainability 2021, 13, 3058. [CrossRef] 
7. Youmans, K.; Villanueva, I.; Nadelson, L.; Bouwma-Gearhart, J.; Lenz, A.; Lanci, S. Engineering students' perceived value of makerspaces in relation to future career preparation. In Proceedings of the International Symposium on Academic Makerspaces, Stanford, CA, USA, 3-5 August 2018.

8. Hynes, M.; Hynes, W.J. If you build it, will they come? Student preferences for makerspace environments in higher education. Int. J. Tech. Des. Educ. 2018, 28, 867-883. [CrossRef]

9. Greene, M.; Kellam, N.; Coley, B. Black men in the making: Engaging in maker spaces promotes agency and identity for black males in engineering. In Proceedings of the Collaborative Network for Engineering and Computing Diversity Conference, Crystal City, VA, USA, 29 April-2 May 2018.

10. Roland, W.; Hui, J.; Gerber, E.M. University makerspaces: Opportunities to support equitable participation for women in engineering. Int. J. Eng. Educ. 2018, 34, 751-768.

11. Villanueva, I.; Downey, R.J.; Tanoe, C.; Choi, Y.H.; Bouwma-Gearhart, J.; Nadelson, L. Designing for equitable access in engineering education spaces for making. Soc. Sci. under review.

12. Fasso, W.; Knight, B.A. Identity development in school makerspaces: Intentional design. Int. J. Technol. Des. Educ. 2020, 30, 275-294. [CrossRef]

13. Lenhart, C.; Bouwma-Gearhart, J.; Villanueva, I.; Youmans, K.; Nadelson, L. Engineering faculty members' perception of university makerspaces: Potential affordances for curriculum, instruction practices, and student learning. Int. J. Eng. Ed. 2020, 26, 1196-1207.

14. Nadelson, L.; Villanueva, I.; Bouwma-Gearhart, J.; Soto, E.; Lenhart, C.; Youmans, K.; Choi, Y.H. Student perceptions of and learning in makerspaces embedded in their undergraduate engineering preparation programs. In Proceedings of the Conference of the American Society for Engineering Education (virtual), 22-26 June 2020.

15. Kim, Y.E.; Edouard, K.; Alderfer, K.; Smith, B.K. Making Culture: A National Study of Education Makerspaces; Drexel University: Philadelphia, PA, USA, 2019.

16. Lui, D.; Litts, B.K.; Widman, S.; Walker, J.T.; Kafai, Y.B. Collaborative maker activities in the classroom: Case studies of high school student pairs' interactions in designing electronics textiles. In Proceedings of the 6th Annual Conference on Creativity and Fabrication in Education, New York, NY, USA, 4-6 October 2016.

17. Jones, S. More than an intervention: Strategies for increasing diversity and inclusion in stem. J. Multicult. Educ. 2016, 10, 234-246. [CrossRef]

18. Ogilvie, A.M.; Knight, D.B.; Borrego, M.J.; Fuentes, A.A.; Nava, P.A.; Taylor, V.E. Transfer student pathways to engineering degrees: Progress and preliminary findings from a multi-institutional study based in Texas. In Proceedings of the American Society for Engineering Education Annual Conference and Exposition, New Orleans, LA, USA, 26-29 June 2016.

19. Vossoughi, S.; Hooper, P.K.; Escudé, M. Making through the lens of culture and power: Toward transformative visions for education equity. Harv. Rev. 2016, 86, 206-232. [CrossRef]

20. Barton, A.C.; Tan, E.; Greenberg, D. The makerspace movement: Sites of possibilities for equitable opportunities to engage underrepresented youth in STEM. Teach. Coll. Rec. 2017, 119, 1-44.

21. Gutiérrez, K.D.; Jaramillo, N.E. Looking for educational equity: The consequences of relying on Brown. Yearb. Natl. Soc. Study Educ. 2006, 105, 173-189. [CrossRef]

22. Kellam, N.N.; Boklage, A.; Coley, B.C.; Liu, Y. Promising practices that promote inclusivity at University affiliated makerspaces within schools of engineering. In Proceedings of the Collaborative Network for Engineering and Computing Diversity, Crystal City, VA, USA, 20 April-2 May 2018.

23. Davishahl, J. Keep it simple and keep it real: Creating inclusive makerspace environments. In Proceedings of the Collaborative Network for Engineering and Computing Diversity Conference (virtual), Tampa, FL, USA, 30 August-1 September 2021.

24. Hagerty, B.M.; Lynch-Sauer, J.; Patusky, K.L.; Bouwsema, M.; Collier, P. Sense of belonging: A vital mental health concept. Arch. Psychiatr. Nurs. 1992, 6, 172-177. [CrossRef]

25. Ryan, R.M.; Deci, E.L. Overview of self-determination theory: An organismic dialectical perspective. In Handbook of SelfDetermination Research; Deci, E.L., Ryan, R.M., Eds.; University of Rochester Press: Rochester, NY, USA, 2002 ; pp. 3-33.

26. Ryan, R.M.; Deci, E.L. Self-Determination Theory: Basic Psychological Needs in Motivation, Development, and Wellness; The Guilford Press: New York, NY, USA, 2017.

27. Trenshaw, K.F.; Revelo, R.A.; Earl, K.A.; Herman, G.L. Using self-determination theory principles to promote engineering students' intrinsic motivation to learn. Int. J. Eng. Educ. 2016, 32, 1194-1207.

28. Alexander, B.K. Performing Black Masculinity: Race, Culture, and Queer Identity; AltaMira Press: Lanham, MD, USA, 2006.

29. How to Create a Culture of Belonging and Why It Matters. Available online: https://nationswell.com/how-to-create-a-cultureof-belonging-and-why-it-matters / (accessed on 5 August 2020).

30. Lanci, S.; Nadelson, L.; Bouwma-Gearhart, J.; Villanueva, I.; Youmans, K.; Lenz, A. Developing a measure of engineering students' makerspace learning, perceptions and interactions. In Proceedings of the American Society of Engineering Education Annual Conference and Exposition, Salt Lake City, UT, USA, 24-27 June 2018.

31. Choi, Y.H.; Bouwma-Gearhart, J.; Villanueva, I.; Nadelson, L.; Soto, E. Engineers in the making: University-affiliated makerspace users' perception of affordances for students' development as engineers. In Proceedings of the ASHE Virtual Conference, New Orleans, LA, USA, 18-21 November 2020.

32. Saldana, J. The Coding Manual for Qualitative Researchers; Sage: Thousand Oaks, CA, USA, 2015. 
33. Premdas, R.R. Identity, ethnicity, and the Caribbean homeland in an era of globalization. Soc. Identities 2010, 17, 811-832. [CrossRef]

34. Sellers, V.; Villanueva, I. What strategies do diverse women in engineering use to cope with situational hidden curriculum? In Proceedings of the American Society of Engineering Education Annual Conference \& Exposition (virtual), Long Beach, CA, USA, 27-30 June 2021; pp. 1-16.

35. Riley, D. Engineering and Social Justice: Synthesis Lectures on Engineers, Technology, and Society; Morgan \& Claypool Publishers: Williston, VT, USA, 2008.

36. Robbins, P.T. The reflexive engineer: Perceptions of integrated development. J. Int. Dev. 2007, 19, 99-110. [CrossRef]

37. Stevens, R.; Amos, D.M.; Garrison, L.; Jocuns, A. Engineering as a lifestyle and a meritocracy of difficulty: Two pervasive beliefs among engineering student and their possible effects. In Proceedings of the American Society of Engineering Education Annual Conference and Exposition, Honolulu, HI, USA, 24-27 June 2007.

38. Lord, S.M.; Camacho, M.M.; Layton, R.A.; Long, R.A.; Ohland, M.W.; Wasburn, M.H. Who's persisting in engineering? A comparative analysis of female and male asian, black, hispanic, native american, and white students. J. Women Minor. Sci. Eng. 2009, 15, 176-190. [CrossRef]

39. Camacho, M.M.; Lord, S.M. The Borderlands of Education: Latinas in Engineering; Lexington Books: Plymouth, UK, 2013.

40. Bailyn, L. Experiencing technical work: A comparison of male and female engineers. Hum. Relat. 1987, 40, 299-312. [CrossRef]

41. Cockburn, C. Caught in the wheels: The high cost of being a female cog in the male machinery of engineering. In The Social Shaping of Technology: How the Refrigerator Got its Hum; Mackenzie, D., Wacjman, J., Eds.; Open University Press: Philadelphia, PA, USA, 1985; pp. 55-65.

42. Hacker, S. The culture of engineering: Woman, workplace and machine. Womens Stud. Int. Q. 1981, 4, 341-353. [CrossRef]

43. Cheryan, S.; Markus, H.R. Masculine defaults: Identifying and mitigating hidden cultural biases. Psychol. Rev. 2020, 127, 122-152. [CrossRef]

44. Secules, S. Making the familiar strange: An ethnographic scholarship of integration contextualizing engineering educational culture as masculine and competitive. Eng. Stud. 2019, 11, 196-219. [CrossRef]

45. Halverson, E.R.; Sheridan, K. The maker movement in education. Harv. Educ. Rev. 2014, 84, 495-504. [CrossRef]

46. Verdin, D.; Smith, J.M.; Lucena, J.C. The influence of connecting funds of knowledge to beliefs about performance, classroom belonging, and graduation certainty for first-generation college students. In Proceedings of the American Society for Engineering Education Annual Conference \& Exposition (virtual), Washington, DC, USA, 22-26 June 2020.

47. Rose, D.H.; Harbour, W.A.; Johnston, C.S.; Daley, S.G.; Abarbanell, L. Universal design for learning in postsecondary education: Reflections on principles and their applications. J. Postsecond. Educ. Disabil. 2006, 19, 135-151.

48. Masters, A.S.; McNair, L.D.; Riley, D.M. Liberatory methodologies: Participatory action research strategies for discovering inclusive maker space practices. In Proceedings of the Institute of Electrical and Electronics Engineers Frontiers in Education Conference, San Jose, CA, USA, 3-6 October 2018. 